\title{
EEN OUD-JAVAANSCHE STEENINSCRIPTIE VAN KONING ER-LANGGA.
}

\author{
Door H. KERN.
}

Behalve de in der tijd bekend gemaakte inscriptie van den beroemden Koning Er-langga ${ }^{1}$, bevindt zich te Calcutta een andere lange inscriptie van denzelfden vorst in 't Oud-javaansch. Hoewel de steen op veel plaatsen geleden heeft, zoodat de letters geheel zijn uitgewischt, is er toch genoeg overgebleven om een uitgave van den tekst, die allerlei belangrijke gegevens bevat, mogelijk te maken. Daarom deel ik dien in transcriptie en, voor zoover als doenlijk, in vertaling mede. De steen waarop de omvangrijke tekst gebeiteld staat, meet M. 1.33 in hoogte, M. 0.96 in breedte, zoodat de regels, 45 in getal, zeer lang zijn ${ }^{2}$.

\section{TEKST.}

1. || O || Swasti çakawarșātîta 963 kārttikamāsa, tithi daçamì çuklapakṣa,, ha, pa, bu, wāra wayang-wayang, cara graha bāyabyastha, uttarabhadravā nakṣatra, ahirbudhnadewatā , bajrayoga - - - ka

2. rạ̣a, bāruṇyamaṇdala, irikā diwaça ny ājñā çrì mahārāja rake halu çrì lokeçwara dharmmawanç̧a airlanggānantawikramottungadewa, tinaḍaḥ rakryān mahāmantrī i hino çrī samarawijaya dha

3. mma suparna - hanata hutungadewa umiñsor i rakryan kanuruhan pu dharmamūrti - - - - - - - - - kě _ - - _ manan, ing barahěm, ing basuri, lmạ̣ ni warggāpinha(y) - - - - - -

1 Bijdragen Kon. Inst. 4, X, p. 1-21.

${ }^{2}$ Het mij uit Batavia toegezonden afdruksel is slechter dan het door Brandes gebruikte, zooals blijkt uit een in zijne nalatenschap gevonden, zeer getrouwe transcriptie. Ik heb die gecollationeerd en daaruit overgenomen wat op mijn afdruksel geheel uitgewischt is. Met $\mathrm{ng}$ geef ik Anuswāra weêr; met ì de gutturale nasaąl. 
4.

ni dharmma karșyan çrī mahārāja. sambandha a

5. n hana ișța prārthanā çrì mahārāja ri kāla ning pralaya ring yawadwìpa, irikang çakakāla 928 mra? — - haji wurawari an wijil sańke lwarām, ekarṇawa rūpa nikang sayawadwìipa rikāng kā

6. la , akweh sira wwang wiçeșa pjaḥ, karuhun an samañkana diwaça çrî̀ mahārāja dewatā pjạ̣ lumāḥ ri sang hyang dharmma parhyañan i wwatan, ring cetramāsa, çakakāla 929, sḍang wāla,

7. ka çrì mahārāja irikāng kāla, prasiddha namblas tahun wayah nira, tapwan dahat kṛtapariçrama nireng sanggrāma, makahetu rarai nira, tapwan enak bańěngi de nira rume

8. gěp saparingkěpany āyudha nira, kunang ri sākṣāt iran wisṇumūrtti, rinakṣa nin sarbwadewata, inahākěn tan ilwa kawaça dening pañawara ning mahāpralaya, mananti ri himbang ni wanagiri, ma

9. kasambhāsana sang tāpaça suddhācāra, mering lāwan hulun ira - - - nta pratipatti manah nira $\mathrm{n}-\operatorname{tanu}--{ }_{-}$ n — - prahwa ri lbū ni pāduka çrì mahārāja, pu narottama

10. sangjūā nira, sirādi ni hulun çrì mahārāja atisayeng dṛ̣̣abhakti humbat(?) tansạ̣ i ayunan çrì mahārāja, milu walkaladhara pinaka rowang çrì mahārāja manāhāra sāhā

11. ra sang bhikṣuka wanaprașțha, yata niwiṣad i çrì mahārāja rikā bhawanan bhațāra rin ahorātra, nimitta ni mahābhāra ny asiḥ ning sarbwadewata i çrì mahārāja, an sira pi

12. nratyaya ning sarbwadewata, - lpapādi padamölana bhuwana, kumalilirana kulit kaki, makadrabya rājalakṣmì, muwahakna harșa nikanang rāt, _ _ _ - sang hyang sarbwadharmma,

13. humarișțākna hanitu ning bhuwana, mangkanābhimata ning sarbwadewata i çrì mahārāja, huwus tạ çrì mahārāja kṛtasañgskāra pratișțha ring sinhhāsana, mwang an kapūja (?) - - pitu çrì ma.

14. hārāja haji dewatā sang lumāh ring iç̧ānabajra ikanang halu pinaka kapratisthān çrì mahārāja, matañ yan rake halu çrì lokeçwara dharmmawaṅça airlanggānantawikra

15. mottungadewasangjñā kāstwan çrì mahārāja, de mpuńku sogata maheçwara mahābrāhmaṇa irikang çakakāla 941 tanpahìnan çrì mahārāja _ _ — kě

16. n sābh(i)mata ning sarbwadewatā i sira, kapwa kakal 
imban (?) ing kriyā wāhyāntara de nira tansalimur i kadharmman ing prajā - mahārāja

17. - nika sinho — - nira, mara _ _ _ - ni sakweh nikāng — —, sapinakahanitu ni yawadwìpa, prabheda _ _ _ — -

18. ¿̀ inarani $\ldots \ldots$ kekale mwang —, nirawaçeșa ikā - - de çrì mahārāja nuni nunï haji — - -

19. tahun an - - diri (?) $-\ldots-1-$ rika $-\ldots-\ldots-$ ikanang sarat pinjahan, ing _ — mwang irikāng çakakāla 951 ri kanang pitu (?) lumampah

20. ta çrì mahārāja dumon ikāng para $-\ldots-\ldots$ guru tumañgal - ddhya deça ni wu? ratan, atiçayeng mahābala

21. samāhwayan pahạ̣phạ̣pan mwang haji wěnkěr, kawaça ta ikā de çrì mahārāja irikāng çakakāla 952 mañkin — — hanitu - - h tu

22. mingalakěn karājyan ira mulih(e) kaḍatwan $\mathrm{i}-$ wā tinūt? nikāng deça galụ̣ mwang deça barat, an tinkān sināhāsan irikāng çakakāla 953 - mahārā

23. ja, - — — h ata ika de çrì mahārāja irikāng çakakāla 954 sahana ni wargga la $-\ldots$ mwang harp $-\ldots$

24. - - - - lāwan sahana nikang - - - - - dc çrì mahārāja, haji wurawari tuwi çrì mahārāja ata mako (?)

25. puruṣa — - kahilang nira, $-\ldots$ çrì mahārāja mwang rakryān kanuruhan pu narottama, rakryān kuninan pu nìti, ri kāla çrì mahārāja haneng magěhan (?)

26. - - hìnan ya - çrì mahārāja, sañka ni hilang sahana ni hanihanitu ni yawadwìpa, kunang krama ni kahilang haji wěn̉kěr de çrì mahărāja - swa? kaḍatwan ira ri ta

27. pa sira - pratinayaka hinārohara deça nirān̉kěn asujimāsa de çrì mahārāja, muwaḥ irikāng çakakāla 957 wwaya ta samañkana ta sira $-\ldots$ - (pa)

28. rājaya ri tapa de çrì mahārāja, sirāmriḥ manusup amet deça durgga, matingal tanaya dāra tka ring rājadrabya rājawahana prakāra, ri kahlema

29. nya irikāng çakakāla 959 - rěp manusup haji ri kapang mwang bala nira samāsị̣ ri sira, kawnang sira ri sarasa ratu wani pa - panan . - - - pinaka ta

30. pakan kaṇḍa sira de çrì mahārāja apalingih moḍoḍa ri sin̉hāsana, sampun sangkșipta ikāng pralaya ri yawadwìpa, matlasan ikā sanggrāma, (ta) 
31. n hana sangçaya ni manah nikāng — — — maka — - yan acchāyā ni pāduka mahārāja, matanya siddhākěn pratijñā nira, madaměl yaça pa

32. tapān ing pucanaan ista $-\mathrm{s}$ an rake yānkěn mantra stawa namaskāra çrì bhațāra hari sāri, mwang palingāna nikang rāt, karuhun sañ añā

33. gataprabhu tkā ri dlāha ning dlāha, ri krama ni de çrì̀ mahārāja munajikakěn sāçwatā ning yawadwìpa, āpan sañ anādi prabhu sakweh nira siniwi ring

34. yawadwìpa $-\ldots-\ldots-\ldots-$ nira, tkā, mángih hayu nira kabeh ring anādi, tātan mañkana çrì mahārāja -

35.

nira mwang abhimata çrî̀ mahārāja maywa

36. — - ni — — — hino madrabya haji mā su 1 - - - - - - - nikāng

37. yaça patapān i pucañan, mantěn tā ikāng lmaḥ ri pucanaan i barahĕm i basuri — - - - - -

38. — - - - - sang hyang yaça patapān i pucañan tan katamāna de ning ${ }^{1}$ winawa sang māna (katrìni,) pa

39. ṅkur, tawan, tirip, mwang nāyaka,' partyaya, pin̉hai wahuta rāma, mwang sakweh sang manilāla drabya haji $\mathrm{m}-$

40. sukha duhkha, sakweh lwiranya - - - - - sahînan i lmặ sang hyang yaça patapān i pucañan _ _ _ _ _ _ _

41. - _ - _ - (sañ mañilāla) drabya haji wulu wulu mwang - - -

42. sina ta lwiranya, luměbu — — - sang hyang yaça patapān i pucañan, yan brāhmaṇa, kṣatriya, weçya, sudra, caṇḍāla, nāyaka, partyaya,

43. pinhai wahuta rāma $-\ldots-\ldots-\ldots$ umulahulaha kaçwatantrān sang hyang dharmma patapān i pucañan mwang sahìnan ing lmặ ni

44. — — nira i hino _ _ _ — — sang hyang yaça patapān, jaḥ tasmāt kabwat karmmā knanya, caṇḍi nira - mahā

45. pātaka - - - - - - - - - - citralekha i pāduka çrì mahāraja $-\ldots$ sira $--\cdots$

46. sang hyang ājñā haji praçāsti

1 De aanvulling in cursief volgens $\mathrm{Kawi}$ Oorkonden VII, $3 b, 4 ; 6 a, 6$, en $6 b, 1$. 


\section{VERTALING.}

1. Heil! 't Çakajaar verloopen 963, maand Kārttika, den $10^{\text {den }}$ van de lichte maandhelft, Haryang ${ }^{1}$, Pahing ${ }^{2}$, Woensdag, Wayang-wayang ${ }^{3}$, stand der planeet Noordestelijk, sterrebeeld Uttarabhadrapadā ${ }^{4}$, godheid Ahirbudhṇa, Yoga Bajra,

2. Karana - kring van Waruṇa; dat is de dagteekening van 't bevel van Z. Maj. den Grootkoning Rake Halu, Z. Maj. Lokeçwara Dharmawaṁça ${ }^{5}$ Airlangga ${ }^{6}$ Anantawikrama Uttunggadewa, ontvangen door Rakryan den hoofdmantri i hino, Z. Exc. Samarawijaya

3. - - Suparṇa - - Uttunggadewa, verstrekt ${ }^{7}$ aan Rakryan den Kanuruhan Heer Dharmamūrti - - - - te Barahěm (en) te Basuri, grond van 't genootschap der

4. Witte monniken ${ }^{8}--\ldots-\ldots--\ldots$ afgebakend moet worden ten behoeve van de oprichting van een gewijd gebied van Rși's ${ }^{9}$ door Z. Maj. den

5. Grootkoning. De aanleiding is: de wensch en 't verlangen van Z. Maj. den Grootkoning ten tijde van den grooten vloed van rampen ${ }^{10}$ op het eiland Java in 't Çakajaar 938 - vorst Wurawari ${ }^{11}$ toen hij uitkwam van Luarām; geheel Java

6. zag er te dien tijde uit als ééne zee, vele hoogaanzienlijke personen sneuvelden, in de eerste plaats sneuvelde. op dat

1 De $2^{\text {de }}$ van de zesdaagsche week.

2 De $2^{\text {de }}$ van de vijfdaagsche week.

3 De 27sto Wuku.

- Een verkorte vorm Bhādrawā komt ook voor op een inseriptie te Bodh Gayā, Archaeol. Survey of India, Annual Report,1908-9,p. 150.

5 D. i. Uit het geslacht van Dharma.

6 A ir was een verouderde spelling reeds tegen 1000 A. D. Men sprak uit er, zooals o. a. blijkt uit den vorm van den naam in 't Sanskritgedicht op Erlangga.

7 Eigenlijk "nederkomend", umingsor. Het wordt gezegd van een bevel van hoogere ambtenaren aan lagere. Onnoodig te zeggen dat het Jav. da w wh (reeds Oj.) denzelfden begripsovergang vertoont.

8 A pinghay, wit; hier m. i. een vertaling van Skr, pāṇ ḍarin.

9 Karșyan is een afleiding vau Skr. r̦și. Onder r̦și heeft men, m.i. te verstaan brahmaansche heremieten. Vgl. Bijdr. D. 67,380 .

10 Pralaya, oplossing, vernietiging; vooral ook gebruikelijk in den zin van ondergang der wereld; hier figuurlijk; in 't Fransch zou men het kunnen vertalen met "débacle".

11 Wurawari, Njav. worawari; of het hier een persoon, dan wel een plaatsnaam is, blijkt niet. 
tijdstip Z. Maj. de Grootkoning zaliger, die begraven ligt in 't heiligdom te Wwatan, in de maand Caitra van 't Çakajaar 939, toen Z. Maj. de Grootko-

7. ning ter tijd nog een jongen was; hij was namelijk 16 jaar oud, nog niet zeer geoefend in 't krijgsbedrijf, uit hoofde van zijn knapenleeftijd, nog niet voldoende

8. krachtig (?) om een volledige wapenrusting te hanteeren. Doch daar hij als een verschijningsvorm was van Wiṣnu, werd hij behoed door alle goden, voorbestemd om niet mede overweldigd te worden door de moeielijkheden der groote beroering: hij verbleef aan den kant van Wanagiri, ${ }^{1}$, sa-

9. menwonende ${ }^{2}$ met heremieten van reinen wandel, vergezeld van zijne dienaren $-\ldots-\ldots$ vastbesloten (o f: eerbiedig) zijn (of hun) geest $-\ldots-\ldots-\ldots$ onvergelijkelijk ${ }^{3}-\ldots$ neergebogen in 't stof van de voeten van Z. Maj. den Grootkoning,

10. Heer Narottama was zijn naam; hij was de eerste van de dienaren van $Z$. Maj. den Grootkoning, buitengemeen trouw gehecht, - , steeds in tegenwoordigheid van Z. Maj. den Grootkoning, mede een kleed van boomschors dragende als gezel van Z. Maj. den Grootkoning,

11. 't voedsel nuttigende van de monniken en heremieten; voorts bleef hij bij $\mathrm{Z}$. Maj. den Grootkoning in 't Godshnis dag en nacht, om 't groot gewicht der liefde van alle goden jegens Z. Maj. den Grootkoning, die

12. door alle goden vast bestemd was dat hij weinig moeite ${ }^{4}$ zou hebben om voor de wereld te zorgen, den rang der voorouders te beërven, in 't bezit te komen van de koninklijke heerlijkheid, de vreugde der wereld te hernieuwen, alle vrome stichtingen (of heiligdommen)

13. - - de booze geesten ${ }^{5}$, der wereld onschadelijk te maken. Zoo was het toegedacht door alle goden aan Z. Maj. den Grootkoning. Nadat Z. Maj. de Grootkoning de wijding ontvangen had, besteeg hij den troon, en toen door Z. Maj. den Grootkoning ook vereering (?)

1 Kan ook als appellatief beteekenen „woudberg."

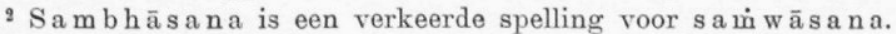

3 Verondersteld dat tan $\mathrm{u}$ - aangevuld moet worden met $\mathrm{pama.}$

4 Verondersteld dat bedoeld is al pāpad.

${ }^{5}$ In overdrachtelijken zin kunnen hiermeê booze vijandelijke geweldenaars bedoeld zijn. Ook ons "duivel" wordt op menschen toegepast. 
14. gebracht was aan den vergoddelijkten vorst die begraven ligt te $\bar{I}_{c} \bar{a}$ nabajra ${ }^{1}$ werd (de plaats genaamd) Halu ${ }^{2}$ door $\mathrm{Z}$. Maj. den Grootkoning tot een gewijd gebied gemaakt. Weshalve hij onder den naam van Rake H̀alu, Z. Maj. Lokeçwara Dharmawańca (uit Dharma's geslacht) Air-

15. langga Anantawikrama Uttungadewa met zegen bevestigd werd door de Hoogwaardigen der Buddhisten, Çiwaieten en Brahmanen in den jare 941. Ontel-

16. baar - Z. Maj. de Grootkoning - volgens de goedgezindheid van alle goden jegens hem. Alle vormen (?) van handelingen, openbare eu geheime, werden door hem, die een open oog had voor de plichten jegens de onderdanen, - - Grootkoning

17. — van 't zijn ; hij ging - _ - — alle die — , alle die als booze geesten van 't elland Java waren, - _ -

18. die gehouden werden voor $-\ldots-$ en $-\ldots$, tot den laatsten toe werden zij door Z. Maj. den Grootkoning $-{ }^{3}$, in

19. de eerste plaats Vorst $-\ldots-$ jaar $-\ldots-\ldots-$ in 't geheele rijk gedood, in -, en in 't Çakajaar 951, in de $7^{\text {de }}$ maand trok

20. Z. Maj. de Grootkoning op ten strijde tegen den vijand - - Woensdag, met nieuwe maan, - desa Wuratan(?), een zeer groot leger - - - -

21. strijd met het front gekeerd tegen den Vorst van Wengkěr. Die werd toen door Z. Maj. den Grootkoning overwonnen in 't Çakajaar 952. Hoe langer zoo meer _ - _ -

22. lieten de kwelgeesten hun koninkrijk in den steek om naar den Kraton in - , - - daarna in 't oord Galuh en 't oord Barut, waar zij aangevallen en overweldigd werden in 't Çakajaar 953 - -

23. Z. Maj. de(n) Grootkoning. -- vervolgens werden door Z. Maj. den Grootkoning in 't Çakajaar $954-$ allen van de afdeeling $-\ldots$ en $-\ldots-\ldots-\ldots$

4 De persoonsnaam is hier elliptisch gebruikt voor de naar hem genoemde plaats. Zoo heet het elders: „die begraven ligt te Çiwabuddha." Ook wij zeggen bijv. : in St. Pieter", bedoelende "in den dom van St. Pieter".

${ }^{2}$ Halu komt voor als plaatsnaam in Kawi Oorkonde XXII regel 3. De eigenlijke beteekenis blijft ondanks art. halu in KBWdb. onopgehelderd.

s Het onleesbare woord zal wel "uitgeroeid" of "onderdrukt" of iets dgl. beteekend hebben. 
24. _ - _ - en allen van de - - _ - door $Z$. Maj. den Grootkoning, de Vorst van Wurawari, ook,

25. Z. Maj. de Grootkoning betoonde zich een held (?) - - hun vernietiging. - - Z Z. Maj. de Grootkoning met den Rakryān Kanuruhan Heer Narottama, den Rakryān Kuningan Heer Nitti. Ten tijde dat Z. Maj. de Grootko-

26. ning te Magehan (?) was, was onbegrensd ${ }^{1}$ de roem (?) van $Z$. Maj. den Grootkoning ten gevolge der verdelging van verschillende kwelgeesten van 't eiland Java. Wat betreft de wijze waarop de Vorst van Wěngkěr door Z. Maj. den Grootkoning uit den weg werd geruimd, hij (hield zich op) in zijn Kraton, in Tapa ${ }^{2}$ zonder

27. tegenweer $^{3}$ te bieden, terwijl zijn land herhaaldelijk in de maand $\bar{A}_{\text {çwina }}{ }^{4}$ verontrust werd door Z. Maj. den Grootkoning. Voorts in 't Çakajaar 957, toen was het dat

28. hij in Tapa door Z. Maj. den Grootkoning overwonnen werd; hij poogde weg te sluipen, een moeielijk genaakbaar oord te zoeken, verliet kinderen en vrouw mitsgaders zijn kcninklijke schatten, veelsoortige koninklijke

29. voertuigen; later, in 't Çakajaar 959, wilde die Vorst wegsluipen naar Kapang met zijn troepen die hem (nog) genegen waren, doch $\mathrm{zij}$ werden overmeesterd te Sarasa ${ }^{5} \ldots$

30. zij $^{6}$ werden tot voetonderlaag gemaakt door Z. Maj. den Grootkoning die met de voeten omlaag ${ }^{7}$ op den troon zat. De beroering op 't eiland Java was te niet gedaan, de oorlogen hadden een einde genomen;

31. geen ongerustheid koesterden de gemoederen der - $\ldots{ }^{8}$ dat zij de (beschermende) schaduw van Z. Maj. den Grootkoning genoten. Daarom volbracht hij zijne

1 Verondersteld dat de onleesbare karakters voor hīna zijn tanpa, en dat y a een overblijfsel is van y a ça.

2 Ik vat het op als plaatsnaam; „in ascese" schijnt mij toe niet passen.

${ }^{3} \mathrm{Ik}$ neem aan dat de de uitgewischte letter vóór pra ${ }^{\circ}$ een $a$ is.

4 Deze maand werd als gunstig tijdstip beschouwd voor expedities.

5 De woordscheiding, en dus ook de plaatsnaam onzeker.

6 De onderworpen of vijandelijke vorsten.

7 De koning zit op Europeesche wijze op den troon, omdat aan zijne voeten de hulde van de onderworpenen gebracht wordt.

$s$ In 't onleesbare gedeelte zal zoo iets als "onderdanen, die 't vaste vertrouwen hadden" gestaan hebben.

Dl. 67 . 
32. gelofte, stichtte de kluizenarij van Pucangan $-{ }^{1}$, gelijk Z. Maj. de Grootkoning gebeden, lof, aanbidding gericht had tot God Hari (Wiṣṇu) steeds (?), en om een voorbeeld (?) te zijn voor de wereld,

33. in de eerste plaats voor de toekomstige heerschers tot in lengte van dagen, op de wijze waarop Z. Maj. de Grootkoning een heilige gelofte deed voor 't bestendig heil van geheel Java, want de overoude (?) heerschers,

34. zoovelen als op Java regeerden $-\ldots+-\ldots-$ ondervonden allen in 't verleden voorspoed. Volstrekt niet Z. Maj. de Grootkoning -

35 .

en de wil van Z. Maj. den Grootkoning -

36. _ _ - (de hoofdmantri i Hino — heffende aan belasting 1 goudstuk -------------- - van de

37. kluizenarij te Pucangan. De gronden te Pucangan, te Barahĕm, te Basuri houden dan op - - - - - - - -

38. — - - - _ - - de heilige kluizenarij te Pucangan (mag niet betreden worden door sol-

39. daten 2, Pańkurs, Tawans, Tirips, en Nāyaka's, Partyaya's, ${ }^{3}$ Witte monniken, Wahuta's, dorpshoofden, en allen die belastingen eischen (?) - - - - - - - - -

40. lusten en lasten, alle van welken aard ook - - zoover als zich uitstrekken de gronden van de heilige kluizenarij te Pucangan - - - - - -

41. - - - - - - (invorderaars) van belastingen ${ }^{4}$, lijfknechten (?) en - - -

42. alwie van welken aard ook, komende binnen _ - - de heilige kluizenarij te Pucangan, hetzij een Brahmaan, Kṣatriya, Waiçya, Çūdra, Cạ̣ḍāla, Nāyaka,

1 Misschien: „zijn wensch wanneer hij eenmaal als een Rake geworden was"; verondersteld dat $s$ vóór an 't overblijfel is van huwus.

${ }^{2}$ Winawa (vertaling van Skr. bhṛta, bhṛtya) is „onderhoorige manschap"; de eigenlijke beteekenis van mānakatriṇ̃i, welke laatste bestanddeel "drietal" aanduidt, ken ik niet. Win a w a beantwoordt hier zonder twijfel aan Skr. cārabhața.

3 Partyaya, elders Pratyaya. Een der beteekenissen van Skr. praty a y a is volgens Petersb. Wetb. „ein Haushälter, der sein eigenes Feuer hat."

4 Vgl. Kawi Oorkonden VII, $3 b, 6$. 
43. , Wahuta, dorpshoofd $-\ldots-\ldots-$ om te roeren aan den vrijdom van de heilige kluizenarij te Pucangan en zoover als zich uitstrekken de gronden van

44. - _ - de heilige kluizenarij ${ }^{1}$, moge ten gevolge daarvan de straf zijner daad ondergaan ${ }^{2}$, zijn - groote

45. zonde $-\ldots \ldots$ citralekha ${ }^{3}$ an de voeten van $Z$. Maj. den Grootkoning - hij -

46. 't heilige bevel des vorsten, als edict (uitgevaardigd).

In de hier bekend gemaakte inscriptie hebben wij de stichtingsoorkonde van de heilige kluizenarij te Pucangan. Behalve 't bevel van Koning Er-langga tot de stichting, met vermelding van de immuniteiten en privilegies daaraan verleend, wordt, bij wijze van inleiding, kond gedaan welke beweegreden den Koning bezielde om een daad van vroomheid te volbrengen, namelijk de gelofte die hîj in zijne jeugd, toen hij in kommervolle omstandigheden verkeerde, gedaan had aan 't graf van een zijner voorouders, om daar ter plaatse een heilige kluizenarij te stichten, wanneer hij eenmaal de macht daartóe mocht bezitten. Hoe hij na verloop van tijd er in slaagde zijne vijanden te overwinnen en oppermachtig heerscher van Java te worden, wordt tevens in herinnering gebracht, jammer genoeg zeer fragmentarisch. Als aanvulling van de in de oorkonde verzwegen of door de leemten in den tekst niet te herkennen feiten kan strekken wat te lezen staat in 't Sanskrit lofdicht op Er-langga, hetwelk in tekst en vertaling uitgegeven is in Bijdragen van 1885 , blz. $1-21$.

Uit dit gedicht, vs. 11vg. weten wij dat Er-langga de zoon was van Udayana, die identisch schijnt te wezen met den vorst die in de oorkonde, reg. 6 , heet »de koning zaliger die begraven ligt in den graftempel te Wwatan. Doch dit zou niet uitkomen indien het jaartal 899 Çaka, dat evenals de naam Udayana

1 Vgl. KO. VII, $6 a, 6$ : „brāhmāṇa, kṣatriya, waiçya, çudra, mwan apinhay akurug anak-thāni, makādi sang prabhu mantry ānāgata yã wat nmulahulah anugraha pāduka çrĩ mahārāja, irikanang wargga haji i Warahu, mne, hlěm, tka ri dlāha ning dlāha.".

2 Vgl. KO. VII, $6 b, 1$ : „tasmāt kabwat karmma knanya, parikãlanĕn ta ya" enz.

Citralekha beteekent gewoonlijk "schilderstuk", doch wat hier bedoeld is, kan wegens de leemte in den tekst niet vastgesteld worden. 
te Djala-toenda ${ }^{1}$ aangetroffen is, Udayana's sterfjaar ware. Gesteld dat wij hier werkelijk Udayana's laatste rustplaats hebben - hetgeen denkbaar is - , dan kan toch het jaartal 899 geen betrekking hebben op diens dood, want uit onze oorkonde van 963, regel 7, blijkt dat Er-langga in 929 zestien jaar oud was, zoodat het sterfjaar van zijn vader Udayana niet in 899 kan vallen. Het cijfer 899 kan juist zijn, maar is niet het sterfjaar van Udayana.

Wij weten nu met zekerheid dat de stichting van de kluizenarij haar beslag kreeg in 963 Çaka. Dit is volstrekt niet in strijd met wat de dichter van 't lofdicht verhaalt. Uit zijne woorden volgt alleenlijk dat bedoelde stichting plaats had na 952, nadat de edele doorluchtige Koning van het eiland Java zegepralend zich op den van juweelen flonkerenden troon plaatste, nadat hij zijne voeten gezet had op het hoofd zijner vijanden». Dan gaat de dichter aldus voort: "Thans, na het Oosterı, Zuiden en Westen veroverd en alle vijanden verslagen te hebben, na alleenheerscher geworden te zijn van het gansche land, wordt Zijne Majesteit Er-langa door de koninklijke Fortuin, welke geenen anderen vermag aan te zien, dicht in hare schoone armen gekneld». Eerst daarop wordt de stichting van de kluizenarij te Pucangan in schitterende kleuren geschilderd. ${ }^{2}$

Een feit van belang dat men in de schenkingsoorkonde niet aantreft, is het huwelijk van den jeugdigen Er-langga met de dochter van den heerscher van Oost-Java, als wiens geslachtsnaam wordt opgegeven Dharmawangça. ${ }^{3}$

Volgens den dichter (vs. 15) "kwamen tot den doorluchtigen monarch, Koning Er-langa, de onderdanen en de voornaamste Brahmanen, met innig verlangen, en, eerbiedig gebogen, richtten zij vol vertrouwen de bede tot hem: "Beheersch het land tot de uiterste grens!» Dit geschiedde in 932». In 't edict

1 Zie Verberk, Oudheden van Java, blz. 242, vgl. 303.

2 Zoo verbetere men 957 (vs. 30), wat dan ook de verklaring van makamogelijk een fout van den steenhouwer voor $\mathrm{mukha}$, zijn moge. Ook in vs. 28 is 959 ' $t$ ware eijfer, zooals trouwens reeds uit de toegevoegde noot over lapana blijkt. In rs. 29 is muni duidelijk $=7$, wat ik niet kan verklaren.

s In 't gedicht vs. 13, waar in de vertaling door een onwillekeurig verzuim 't woord Dharmawangça uitgevallen is. Uit de oorkonde blijkt dat Er-langga dien geslachtsnaam bij zijne overige titels voegt, daarmede zeker als rechtmatig opvolger zijns schoonvaders optredende. 
wordt zulks niet vermeld; wel echter dat hij reeds in 941 zóó machtig was, dat hij zijne voIledige heerscherstitels kon aannemen, met inzegening van de geestelijkheid der verschillende gezindten.

$\mathrm{Na}$ genoemd tijdstip had Er-langga nog menigen strijd te voeren tegen meer dan één vijand. Zoo beoorloogde hij den Vorst van Wĕngkĕr, dien hij in een veldslag in 952 overwon, en wiens land hij in 953 teisterde. Hierop kan doelen hetgeen de dichter verhaalt in vs. 25, namelijk dat Er-langga de residentie des vijands verbrandde en in 953 diens steden herhaaldelijk blakerde. Wegens een leemte in den tekst van 't gedicht, vs. 23, en de nog grootere gebreken in de oorkonde, (regel $20-23$ ), is niet met zekerheid op te maken, of dezelfde vijand of vijanden bedoeld zijn.

De dichter maakt in vs. 28 gewag van een schitterende overwinning, door Er-langga bevochten op zekeren Koning Wijaya, den $13^{\text {den }}$ der lichte helft van de maand Bhādrapada, van 't jaar $959^{1}$. Onverklaarbaar nu is het dat in 't volgende vs. verteld wordt hoe Wijaya aan zijn einde kwam in de maand Kārttika van 957. Dit is natuurlijk onmogelijk: er moet in muni, getalwaarde 7 , een fout schuilen, mogelijk een lapsus voor $\mathrm{mukha}^{2}$. Vergelijken wij nu de gegevens in de oorkonde, regel 29 in verband met regel 27, dan komen wij tot het besluit dat de vorst van Wěngkĕr en Wijaya één en dezelfde persoon zijn, al is de voorstelling van 't beloop der feiten in onze beide bronnen eenigszins onderling afwijkend.

Afgescheiden van den onvoldoenden toestand van den tekst, waardoor veel voor ons onverstaanbaar blijft, ondervinden wij moeielijkheden wanneer het er op aankomt de ligging der in 't stuk genoemde plaatsen te bepalen. Om te beginnen met Pucangan, in 't Sanskrit terecht vertaald met Pūgawat. Na een plaatselijk onderzoek is de Heer Rouffaer tot het besluit gekomen dat Pucangan de berg Pernanggoengan is, de noordelijke voorberg van den Ardjoena, alwaar te Djala Toenda (zie Verbeek's kaart bij zijn "Oudheden van Java») aan den Westelijken voet gevonden is 't opschrift Udayana en 't jaartal 899 Çaka ${ }^{3}$.

1 Volgens verbetering; zie de Aanteekening 2 op voorgaande blz.

2 Men houde in 't oog dat de maand Kārttika later is dan Bhārdrapada.

Dat Udayana daar begraven ligt, is zeer wel mogelijk, maar 899 kan niet zijn sterfjaar wezen; zie boven. 
Wwatan, waar volgens regel 6 der oorkonde een heiligdom was, is zeker wel het tegenwoordige Wotan, in District Mantoep, Afd. Lamongan, Res. Soerabaja, waar een beschreven steen gevonden is ${ }^{\mathbf{1}}$.

Wengkĕr is de naam der hoofdplaats van een gebied waarvan in later tijd, in 't Madjapahitsche tijdperk, herhaaldelijk sprake is ${ }^{2}$.

In regel 14 wordt een begraafplaats van een vorst, zeker wel een graftempel, aangeduid als "Içāna-bajra». Dit is eigenlijk de bijnaam van een vorst, maar van welken? In 't Kamahāyānikan ${ }^{3}$ vinden wij als titel van Mpu Siṇ̣ok opgegeven: Çri İçānabhadrottunga[1]-dewa. Dezelfde vorst wordt in 't Sanskrit lofdicht op Er-langga aangeduid met den titel van Çrî Iç̧ānatunga. In een oorkonde van 861 Çaka draagt hij den titel van Çrì İçāna Wijaya Dharmottungadewa; in een ander van 851 Çrí Içāna Wikramottungadewa. In Kawi Oorkonde VII betitelt Mpu Seṇdok zich als Dakșottama Bahubajra (lees: $\mathrm{Ba}^{\circ}$ ) Pratipakșakṣaya. Zoo ook in K.O. XVII. Ondanks de alleszins verklaarbare on-

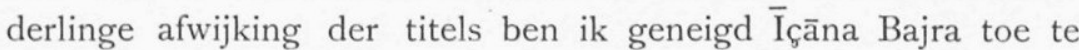
passen op Mpu Siṇ̣ok, te meer omdat bajra deel uitmaakt van bāhubajra, en ook omdat hij een der voorouders van moederszijde van Er-langga was, zoodat de vereering, door dezen aan de rustplaats van zijn voorvader bewezen, zeer natuurlijk is. De vraag aangaande de ligging der plaats is echter daarmeê nog niet opgelost.

Aan een onderzoek naar de overige plaatsnamen zal ik mij niet wagen, te minder omdat van ettelijke de lezing alles behalve vaststaat.

1 Zie Verbeek, op c. No 431.

${ }^{2}$ Zie Brandes, Pararaton, blz. 256, onder Wĕngkĕr. Ook in de Nāgarakrtāgama komt de naam herhaaldelijk voor.

3 Uitg. van Kats, blz. 118. 